\title{
1997: Global links, world wide web and much more!
}

\section{Peter Corr}

$M B C h B, F F R A D(D) S A, F R C R$, $M$ Med(UCT)

Department of Radiology, University of Natal
B y the time you read this, 1997 will be around the corner! SAJR has successfully survived its first year!

As South Africa is an Indian Ocean rim country, we have established ties with the Singapore Radiology Society and their journal: Diagnostic Clinics in the Singapore Medical Journal (SMJ). We will be publishing in this edition a reprint of a case report from the Diagnostic Clinics Series of the SMJ. We hope to exchange case reports with the $S M J$ on a regular basis.

We hope that you are able to visit the journal on the world wide web at http://wwwimed.co.za/rssa, the home page of RSSA, where you will find a wealth of useful information with links to radiology societies around the world. The exponential growth of the internet is changing the way we work, find information and communicate. South Africa and SA radiology is well placed to take advantage of our lead in this phenomenon. Software development has allowed the generation of radiological reports that can be transmitted by e-mail and the internet. It is only a matter of time before radiological images will follow!

I wish you and your family a peaceful and happy new year.

\section{TheEditor}

